\title{
El uso de Facebook como herramienta de comunicación turística en los grandes destinos urbanos internacionales
}

\section{The use of Facebook as a tourist communication tool in major international urban destinations}

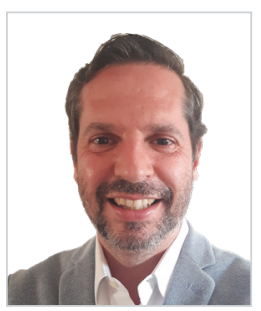

Francisco Manuel Pastor Marín. Profesor de Teoría de la Comunicación de la UNIR. Licenciado en Periodismo por la Universidad de Málaga. Máster en Comunicación Política y Electoral por la Universidad Autónoma de Barcelona. Posgrado en Marketing y Comunicación de los Destinos Turísticos Sostenibles. Consultor de comunicación turística. Facilitador de la Organización Mundial del Turismo (OMT-UNWTO). Formador del Centro Internacional de Formación de Autoridades y Líderes (CIFAL), dependiente de la agencia de Naciones Unidas UNITAR. Ha sido responsable de Comunicación del Área de Turismo y director de Información y Participación Digital en el Ayuntamiento de Málaga, además de jefe de sección en La Opinión de Málaga.

Universidad de Málaga, España

fmpastor@uma.es

ORCID: 0000-0002-2895-4741

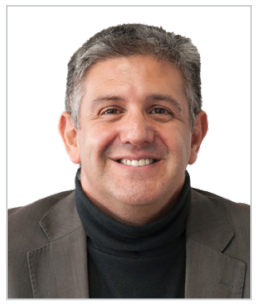

Francisco Javier Paniagua Rojano. Profesor Titular en el Departamento de Periodismo de la Universidad de Málaga, donde imparte docencia en comunicación institucional y corporativa. Es docente invitado en diferentes títulos de posgrado sobre comunicación en las organizaciones. Desde 2008 es secretario de la sección "Comunicación estratégica y organizacional” de la Asociación Española de Investigación de la Comunicación, y ha sido director de comunicación de la Federación Andalucía de Municipios y Provincias y la Universidad Internacional de Andalucía. Ha participado como investigador en diferentes proyectos sobre credibilidad de los medios de comunicación y social media y destinos turísticos, temas sobre los que ha publicado más de 40 artículos en revistas de impacto.

Universidad de Málaga, España

fjpaniagua@uma.es

ORCID: 0000-0001-7376-4536

Recibido: 04/01/2020 - Aceptado: 02/04/2020

Received: 04/01/2020 - Accepted: 02/04/2020

\section{Resumen:}

El objeto de estudio de este trabajo es el análisis de la estrategia de comunicación que aplican diferentes destinos turísticos en Facebook. En concreto se examina la actividad, la capacidad de generar comunidad e interacción; qué temas contribuyen a ello y qué formatos predominan. Se parte de la hipótesis de que los territorios pueden lograr un mayor rendimiento de su presencia en los medios

\section{Abstract:}

The object of study of this work is the analysis of different tourist destinations' communication strategy that is applied to Facebook. More specifically, the activity, the capacity to generate a community and interaction, what themes contribute to it, and what formats predominate are examined. It is based on the hypothesis that territories can achieve higher performance from their presence on

Cómo citar este artículo:

Pastor Marín, F. M. y Paniagua Rojano, F. J. (2020). El uso de Facebook como herramienta de comunicación turística en los grandes destinos urbanos internacionales. Doxa Comunicación, 30, pp. 265-281.

https://doi.org/10.31921/doxacom.n30a14 
sociales. Como técnica metodológica, se propone el análisis de contenido de las páginas oficiales de los destinos incluidos en el estudio 'City Tourism Performance Research' (UNWTO y WTCF, 2017), que recoge casos de éxito en el turismo urbano, a los que se suma Málaga, por el ser el destino urbano de España que más crece. En total, se analizan 2.217 posts compartidos entre febrero y abril de 2019 en las páginas de las ciudades de Amberes, Berlín, Bogotá, Buenos Aires, Copenhague, Ciudad del Cabo, Hangzhou, Linz, Málaga, Marrakech, Pekín, Seúl, Sapporo, Tianjin, Tokio y Turín. Se concluye que los temas que generan más reacciones son aquellos que se corresponden con los elementos visuales y con los atributos diferenciadores de los destinos y se confirma que los territorios mantienen en Facebook una presencia más intuitiva que estratégica.

Palabras clave:

Facebook; turismo; destinos; ciudades; interacción. social media. As a methodological technique, it proposes the content analysis of the official pages of the destinations included in the study "City Tourism Performance Research" (UNWTO and WTCF, 2017). The study provides success stories in urban tourism; Malaga is one of these as it is the fastest-growing urban destination in Spain. 2217 shared posts are analysed between February and April 2019 on the pages of the following cities: Antwerp, Berlin, Bogota, Buenos Aires, Copenhagen, Cape Town, Hangzhou, Linz, Malaga, Marrakech, Beijing, Seoul, Sapporo, Tianjin, Tokyo, and Turin. The conclusion is that the themes that generate the most reactions are those that correspond to visual elements and the differentiating attributes of the destinations. It is also confirmed that the territories maintain a more intuitive rather than strategic presence on Facebook.

Keywords:

Facebook; tourism; destinations; cities; interaction.

\section{Introducción}

El turismo es actualmente uno de los sectores económicos más importantes del mundo. De hecho, la industria turística se está imponiendo como uno de los mejores indicadores para medir la buena salud de la economía, tanto en los países desarrollados como en los emergentes. En 2017 el turismo aportó algo más del 10\% del producto interior bruto (PIB) mundial, generó uno de cada diez puestos de trabajo y representó aproximadamente el 30\% de las exportaciones de servicios en todo el planeta (UNWTO, 2018).

En 2018 se registraron 1.400 millones de llegadas de turistas internacionales en todo el mundo, lo que supone un crecimiento del 6\% con respecto al año anterior. Esta cifra se ha alcanzado dos años antes de lo que preveían las previsiones oficiales (UNWTO, 1998). Dentro de esta tendencia general de crecimiento es el turismo urbano el segmento que está registrando un auge mayor en todo el mundo, por su capacidad para atraer turistas tanto por razones de ocio como de negocio, y se ha convertido en un elemento clave para la economía de las ciudades.

Este crecimiento, sostenido en los últimos años, se ha debido a múltiples factores: la apertura de nuevos mercados, nuevos modelos de negocio, el abaratamiento de los viajes y, por supuesto, la aparición y posterior desarrollo de las Tecnologías de la Información y la Comunicación (TIC) en general e Internet en particular (Buhalis y Law, 2008). En cualquier caso, para el sector turístico los medios sociales han supuesto un punto de inflexión en la comunicación turística (Martínez-Valerio, 2012).

Muchos autores consideran, en este sentido, que los medios sociales han cambiado la comunicación en la web (Rodríguez y De la Morena, 2014) hasta el punto de convertirse en "el modus operandi del siglo XXI" (Lange-Faria y Elliot, 2012). Se puede decir, de hecho, que los medios sociales han transformado la comunicación turística (Xiang y Gretzel, 2010; De San Eugenio 2011; Míguez, Mariné-Roig y Huertas, 2014; Munar y Jacobesen, 2014; Wichels, 2014; Paniagua y Huertas, 2018). 
Esto ha sido así debido fundamentalmente a la gran capacidad que tienen los medios sociales de interacción y de creación de diálogo con sus públicos (Lim, Chung y A Weaber, 2012; Míguez et al., 2014; Altamirano y Túñez López, 2016). Hoy, gracias a los medios sociales, los consumidores conversan entre sí, comparan información de los diferentes destinos turísticos y recomiendan o no sus experiencias (Giraldo y Martínez, 2017).

\subsection{La importancia de la imagen en los destinos turísticos}

La imagen, por tanto, se ha convertido en un elemento fundamental a la hora de elegir un destino turístico (Crompton, 1992), ya que las experiencias que puedan tener los turistas en ese destino servirán de guía de recomendación para familiares, amigos y también para los contactos que puedan tener en los diferentes medios sociales. Así, resulta evidente que los medios sociales están jugando un gran papel como fuente de información de los turistas (Xiang y Gretzel, 2010; Miguéns, Baggio y Costa, 2008) contribuyendo a cambiar el paradigma de la comunicación.

Ahora, el turista se sitúa en el centro de ese paradigma, de manera que el turismo tradicional, organizado y uniformador, ha dado paso al turismo experiencial (De San Eugenio, 2011). Es por ello que las oficinas de marketing de los destinos (OMD) están haciendo cada vez un esfuerzo mayor para consolidar sus marcas con el objetivo de que los turistas se queden con la mejor imagen de estos destinos. El concepto de marca -entendida como conjunto de nombre, logotipo, símbolos y valores que tratan de representar la identidad de un territorio para crear una visión positiva entre sus posibles públicos (Huertas, 2014) - se encuentra así en un complejo proceso de adaptación de los consumidores (Giraldo y Martínez, 2017).

Como servicio que es, el destino turístico es un intangible. Hasta que no disfruta su experiencia en él, el turista no sabrá si ésta será buena o mala (Blain, Levy y Brent Richie, 2005). Por esta intangibilidad, elegir un destino turístico es siempre un riesgo, aunque ahora este riesgo puede ser minimizado gracias a las opiniones de otros turistas (Mill y Morrison, 2012; Mendes Thomas, Augusto Biz y Gândara, 2013), y sus valoraciones serán tenidas en cuenta más que las de las Oficinas de Marketing de Destino (OMD) (Xiang y Gretzel, 2010; Domínguez y Araújo, 2012).

Los destinos se benefician de estos medios en la fase previa al viaje, cuando buscan información que les inspire sobre el lugar que van a visitar; durante el viaje mismo, cuando publican y comparten información; y al volver a sus hogares, cuando comparten las experiencias vividas (Mangold y Faulds, 2009; Mendes Thomaz et al., 2013). De hecho, cada vez más, los turistas publican algún tipo de información en los medios sociales sobre su experiencia vacacional, mostrando una actitud proactiva (Santo, 2014).

Actualmente, los turistas pueden tomar sus decisiones basándose en la información que le ofrecen otros turistas que ya han visitado el destino previamente y no sólo por lo que puedan contarle los responsables de los destinos turísticos (Curty y Zhang, 2011). En este nuevo paradigma de la comunicación turística, los medios ofrecen a los turistas la oportunidad de opinar, puntualizar, pedir información sobre cualquier asunto, criticar su experiencia o alabarla, además de exponer sugerencias de mejora o conocer a otros turistas con gustos similares. Los turistas pueden así convertirse en líderes de opinión, por su capacidad para crear o destruir una reputación (Alvarado, 2012). 
De esta forma, estamos asistiendo a la reinvención del proceso de planificación del viaje (Sanmartín, 2012). Siendo Internet el eje central de búsqueda, los medios sociales pueden ser la nueva "agencia turística" en la que se comparten las experiencias vividas. Por ello, se habla de un nuevo viajero, que ha decidido adquirir sus productos turísticos de forma directa y sin intermediarios (Buhalis y Law, 2008).

En este contexto, es obvio que los destinos han aumentado su necesidad de comunicar y ven en la marca un elemento propio de comunicación (Fernández-Cavia, 2011). Los territorios con una marca potente tienen más fácil atraer a los turistas, pero también a nuevos residentes o futuras inversiones (Morgan, Pritchard y Pride, 2011). Aunque un territorio no es un producto, la mayor parte de los estudios (Fernández-Cavia y Huertas, 2009) consideran que el branding también puede aplicarse a los territorios. De hecho, la marca-territorio es ahora lo que más identifica a un destino turístico (De San Eugenio, 2011).

La imagen de un destino turístico no deja de ser la percepción global que un turista tiene de él (Bigné, Isabel Sánchez y Sánchez, 2001). En este sentido, los medios sociales resultan ser unas magníficas herramientas para contribuir a la buena imagen del destino, facilitando la comunicación como un elemento bidireccional entre la organización y sus públicos (Fernández-Cavia y Huertas, 2014). Su uso permite no sólo saber lo que piensan los viajeros sino también las organizaciones de marketing de los destinos (OMD) puedan entablar diálogo con ellos y abrir la puerta a relaciones futuras (Wigley y Lewis, 2012; Fernández-Cavia y Huertas, 2014; Mariné-Roig y Huertas, 2016).

\subsection{Los medios sociales en los destinos turísticos}

Los medios sociales ofrecen múltiples oportunidades a las instituciones turísticas (Xu, 2010) y contribuyen al establecimiento de la marca del destino (Domínguez y Araújo, 2012). Se trata de que ésta quede fijada en la mente de los turistas, ya que estos elegirán su lugar de vacaciones por la imagen que tenga del destino. Por ello, como explican Folgado, Oliveira y Hernández (2011), el destino intentará subrayar su carácter único mediante el uso de técnicas promocionales que busquen la creación de una marca fuerte y potente.

En el éxito del destino jugará un papel importante la imagen de marca que de él tengan los turistas. Por lo general, los turistas tienen un conocimiento limitado de los destinos turísticos antes de visitarlos. Por tanto, si el destino tiene una imagen de marca fuerte y diferenciada, tendrá más posibilidades de ser incluido en el programa de viaje de los turistas (Beerli y Martín, 2002). Por ello, uno de los principales motivos para usar los medios sociales es mejorar la imagen de marca (Piñeiro, 2012).

Para conseguir una correcta interacción con los turistas y un verdadero diálogo, lógicamente, hace falta una buena gestión de los medios sociales, permitiendo los comentarios y contestándolos. Si sólo se usan las herramientas de forma unidireccional es imposible que se dé el diálogo (Míguez et al., 2014). No en vano, aunque los propios medios sociales, por su tecnología, tienen en sí mismos esa capacidad de interacción (Lovejoy y Saxton, 2012), para que ésta sea efectiva es imprescindible que los gestores de los medios sociales las usen de forma correcta (Zhou y Wang, 2013). Algunos autores (Míguez et al, 2014; Martínez-Sala y Campillo-Alhama, 2018) señalan, sin embargo, que las OMD no están aprovechando todo el potencial que los medios sociales tienen como herramienta para conseguir diálogo con sus públicos. 
Desde su aparición, "los gobiernos a todos los niveles, utilizan Internet principalmente como tablón de anuncios electrónico para publicar su información, sin realizar un verdadero esfuerzo de interacción real” (Castells, 2001) y este modelo parece que se ha mantenido en el caso de la comunicación turística a través de los medios sociales (Martínez-Valerio, 2012). Y ello pese a que el establecimiento de relaciones entre las OMD y los diferentes usuarios es quizá uno de los aspectos más trascendentes de los medios sociales (Altamirano y Túñez-López, 2016).

De esta forma, si bien es cierto que los medios sociales han ofrecido nuevas oportunidades, también han supuesto un reto importante para las instituciones turísticas, así como para los directores de comunicación y los propios gestores de los medios, que en poco tiempo se han tenido que adaptar a una realidad nueva y cambiante. Por lo general, las OMD se están adaptando a esta transformación con gran rapidez y profesionalidad, aunque debido a la celeridad con la que se producen estos cambios, en muchas ocasiones los destinos turísticos están usando los medios sociales sin saber bien en cuáles estar presentes o cuáles son los efectos de sus estrategias, de forma más intuitiva que estratégica (Hvass y Munar, 2012; Hays, Page y Buhalis, 2013).

Todavía hoy se usan estos medios para informar, sin dialogar (Fernández Cavia y Huertas, 2009), por miedo a las críticas o por la falta de formación (Huertas, 2014). Aun así, los medios sociales son el canal más importante que encuentran los dircom para dirigirse a sus públicos y la relevancia queda reflejada en la importancia que les otorgan los propios directores de comunicación. El 90,4\% de los dircom considera que los medios sociales son ya el canal más importante (Zerfass, Moreno, Tech, Vercic y Verhoeven, 2017), por delante de websites, periódicos online, eventos, canales de radio y televisión o periódicos tradicionales. De esta forma, la percepción de la importancia de los medios sociales ha pasado del $10 \%$ en 2007 a más del $90 \%$ una década más tarde.

De hecho, los destinos apuestan cada vez más por este tipo de comunicación, lo que ha conllevado incluso cambios en la estructura de la mayoría de los departamentos de comunicación y marketing de los destinos (Wilches, 2014). No en vano, el uso de los medios sociales obliga a los responsables de comunicación de los destinos a un continuo esfuerzo de actualización (Domínguez y Araújo, 2012).

De todos los medios sociales, Facebook sigue siendo en la actualidad el más utilizado. De hecho, la red fundada por Mark Zuckerberg en 2004 es uno de los sitios web más populares en todo el mundo y cuenta con más de 2.300 millones de usuarios activos mensuales (Facebook, 2018), lo que supone casi la mitad de la población conectada (Internet World Stats, 2018). Facebook se convierte así en una de las organizaciones de medios más grande de la historia (Rieder, 2013).

Facebook es un elemento indispensable para la puesta en marcha de actividades de marketing (Stankov, Klauco, Vujicic, Vasiljevic y Dragicevic, 2016). También en el campo de la comunicación turística, Facebook ha demostrado tener una gran fortaleza ya que su uso se ha comprobado en cada una de las fases de la planificación del viaje, anteriormente descritas: antes del viaje mismo, cuando ayuda a inspirar a los turistas; apoyando la planificación y reserva, y como plataforma para contar las experiencias vividas en el destino (Sparkler, 2014). Es por ello que un discurso coherente en Facebook puede ayudar a los destinos a generar una mejor imagen de marca (Rodríguez, Llorente y García, 2012).

Por lo general, cada vez son más los destinos que se están dando cuenta de la importancia de administrar de forma efectiva los medios sociales para lograr una ventaja competitiva con respecto a otros destinos (Pike y Page, 2014). A pesar de 
la amplia adopción de los medios sociales por parte tanto de los consumidores como de los proveedores turísticos en los últimos años, la práctica exitosa de manipular y administrar estos medios sigue siendo en gran parte desconocida para los profesionales y los académicos (Xiang y Gretzel, 2010; Leung, Law, van Hoof y Buhalis, 2013; Mariani, Di Felice y Mura, 2016).

Hasta el momento, los estudios realizados sobre el uso de los medios sociales por parte de los destinos turísticos sufren una serie de limitaciones metodológicas (Hays et al., 2013) debido, fundamentalmente, a la ausencia de métricas sólidas para capturar el compromiso social (Mariani, Mura y Di Felice, 2018).

A fin de cerrar esta brecha de investigación, llevamos a cabo un estudio con el objetivo de explorar cómo las oficinas de marketing de grandes destinos urbanos están empleando estratégicamente Facebook como herramienta de comunicación turística, ilustrar los diversos grados de uso de esta red social por parte de las ciudades estudiadas, analizar cuáles son los factores que contribuyen a una mayor participación de los turistas o potenciales visitantes e identificar casos de buenas prácticas en el uso de Facebook por parte de estos destinos. Se trata, en definitiva, de conocer qué contenidos generan más reacciones e interactividad entre los turistas.

Hemos decidido centrarnos en Facebook porque, como se ha explicado, esta red es actualmente la que cuenta con un mayor número de seguidores en todo el mundo. Además, más de la mitad de los viajeros de todo el mundo utilizan Facebook para informarse (Observatorio de Redes Sociales, 2019). Partimos de la hipótesis de que los destinos están usando esta red social más de forma intuitiva que estratégica, trabajando poco la interacción con sus públicos y más como lugar de información turística que como punto de encuentro para el diálogo.

\section{Metodología}

Para conseguir los objetivos propuestos, el presente estudio ha analizado los posts publicados por los perfiles oficiales de Facebook de una muestra de 16 destinos urbanos de todo el mundo, publicados entre los meses de febrero y abril de 2019. Este periodo resulta muy interesante porque coincide con importantes periodos vacacionales y sus preparativos en los destinos analizados (Año Nuevo Chino, Primavera, Semana Santa, Pascua).

La selección de la muestra coincide con los 15 destinos del estudio ‘City Tourism Performance Research' (UNWTO y WTCF, 2017), que recoge los casos de éxito y buenas prácticas realizados en algunos de los principales destinos turísticos urbanos del mundo, a los que se suma Málaga por ser destino que más crece en España. De hecho, la capital de la Costa del Sol ha crecido en la última década años casi un $130 \%$ en la cifra de viajeros alojados en hoteles, según los datos de la Encuesta de Ocupación Hotelera del Instituto Nacional de Estadística (INE).

De esta forma, se vincula, además, la actividad investigadora al ámbito de la Universidad en la que se realiza el estudio. Por tanto, conforman la muestra final Málaga, Amberes, Berlín, Bogotá, Buenos Aires, Copenhague, Ciudad del Cabo, Hangzhou, Linz, Marrakech, Pekín, Seúl, Sapporo, Tianjin, Tokio y Turín.

Como técnica metodológica, se propone el análisis de contenido de las páginas oficiales de estos destinos en Facebook. Esta técnica se considera la idónea para para afrontar investigaciones cuantitativas sobre textos escritos, una práctica de 
larga tradición en el los estudios periodísticos; ya que permite el establecimiento de inferencias fiables sobre el contexto de las noticias (Krippendorff, 2002) y sobre sus condiciones de producción y recepción; y se considera de mayor utilidad para para recopilar, procesar y evaluar grandes cantidades de información (Orellana y Sánchez, 2006) y su frecuente utilización en la descripción de los componentes de los mensajes mediáticos (Igartua, 2006).Esta metodología ha sido empleada, además, en estudios anteriores sobre el uso de los medios sociales en destinos turísticos (Míguez, Mariné y Huertas, 2014; Huertas, 2016).

Se han estudiado un total de 2.217 posts a través de la herramienta Fanpage Karma (www.fanpagekarma.com) clasificados por su tipología (fotografía, estado, vídeo o enlace) y según también el número de 'me gusta' recibidos, las comparticiones y comentarios de los usuarios. Posteriormente, se realizó un análisis de contenido de los atractivos turísticos y de los valores emocionales de la marca (patrimonio tangible, paisaje, agenda, clima, naturaleza, servicios, ocio, mensajes institucionales, patrimonio intangible, deporte, negocios, información no turística y tecnología) más mencionados o comunicados por las oficinas de marketing de los destinos (OMD), relacionándolos con los posts que generaban más reacciones.

\section{Resultados}

Los destinos analizados tienen un total de 5.568 .000 seguidores, lo que supone una media de 348.000 seguidores por cada uno de los destinos (Gráfico 1). Las diferencias entre ellos, sin embargo, son notables. Los destinos con mayor número de seguidores son Pekín (1.400.000), Seúl (938.000), Hangzhou (800.000), Buenos Aires (755.000) y Ciudad del Cabo (514.000). En el extremo contrario se encuentran Marrakech (11.000), Bogotá (19.000), Amberes (32.000), Sapporo (36.000) y Turín (40.000).

En el periodo analizado los destinos han publicado un total de 2.217 posts, lo que supone una media de 138,5 post por cada uno de los destinos. También en este caso hay grandes diferencias entre los diferentes destinos. Los que más publican son Bogotá (302), Berlín (237), Marrakech (194), Málaga (182) y Ciudad del Cabo (177). Por el contrario, los destinos con menor actividad en el periodo han sido Sapporo (9), Copenhague (84), Linz (87), Seúl (107) y Tokio (108). Estas cifras demuestran que el número de seguidores no está directamente relacionado con el número de posts publicados. 
Gráfico 1

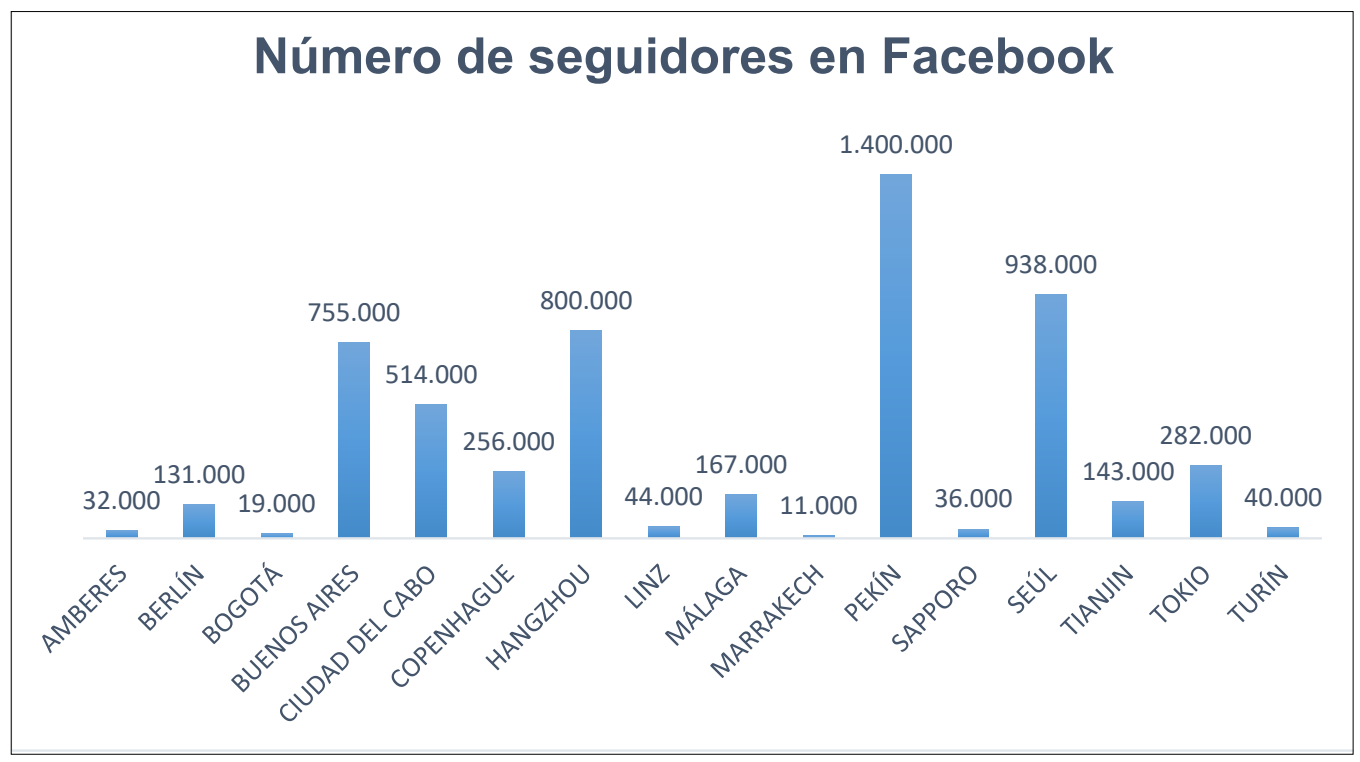

Fuente: elaboración propia

Los tipos de posts se clasifican en link, foto, status y vídeo. Facebook permite enviar con gran facilidad tanto fotos como vídeos. De hecho, la gran mayoría de los posts publicados en este periodo utilizan imágenes (sean fotos o vídeos): 1.718, el 77,49\% del total. Además, todos los destinos, excepto Sapporo utilizan este recurso, por lo que puede afirmarse que el 93,5\% de los destinos hacen uso de las imágenes para sus publicaciones en Facebook. En concreto, del total de posts analizados 1.414 (el 63,7\% del total) tienen fotos, 472 (el 21,2\%) son un enlace o link a alguna otra página web, 304 (el 13,7\%) son vídeos y sólo 27 (el 1,21\%) son únicamente un estado (o status, en la terminología de la red social).

La media de posts 'status' por destino en el periodo analizado es de 1,6. El 62,5\% de los destinos usa este recurso. Los que más lo hacen son Bogotá (7), Buenos Aires (5), Marrakech (5), Turín (4) y Seúl (2). Por debajo de la media se encuentran Ciudad del Cabo (1), Málaga (1), Pekín (1) y Sapporo (1). No obstante, Amberes, Berlín, Copenhague, Hangzhou, Linz, Tianjin y Tokio ni siquiera utilizan este tipo de posts.

El 93,7\% de los destinos postean fotos. La media de posts con fotos es de 88,3 por destino (Gráfico 2). Los destinos que más fotos incluyen en sus posts son Bogotá (162), Marrakech (162), Málaga (150), Turín (118) y Hangzhou (107). Muy por debajo de la media se encuentran Copenhague (29), Seúl (50), Linz (56), Tokio (68) y Berlín (70). Sapporo no posteó ninguna foto. 
Gráfico 2

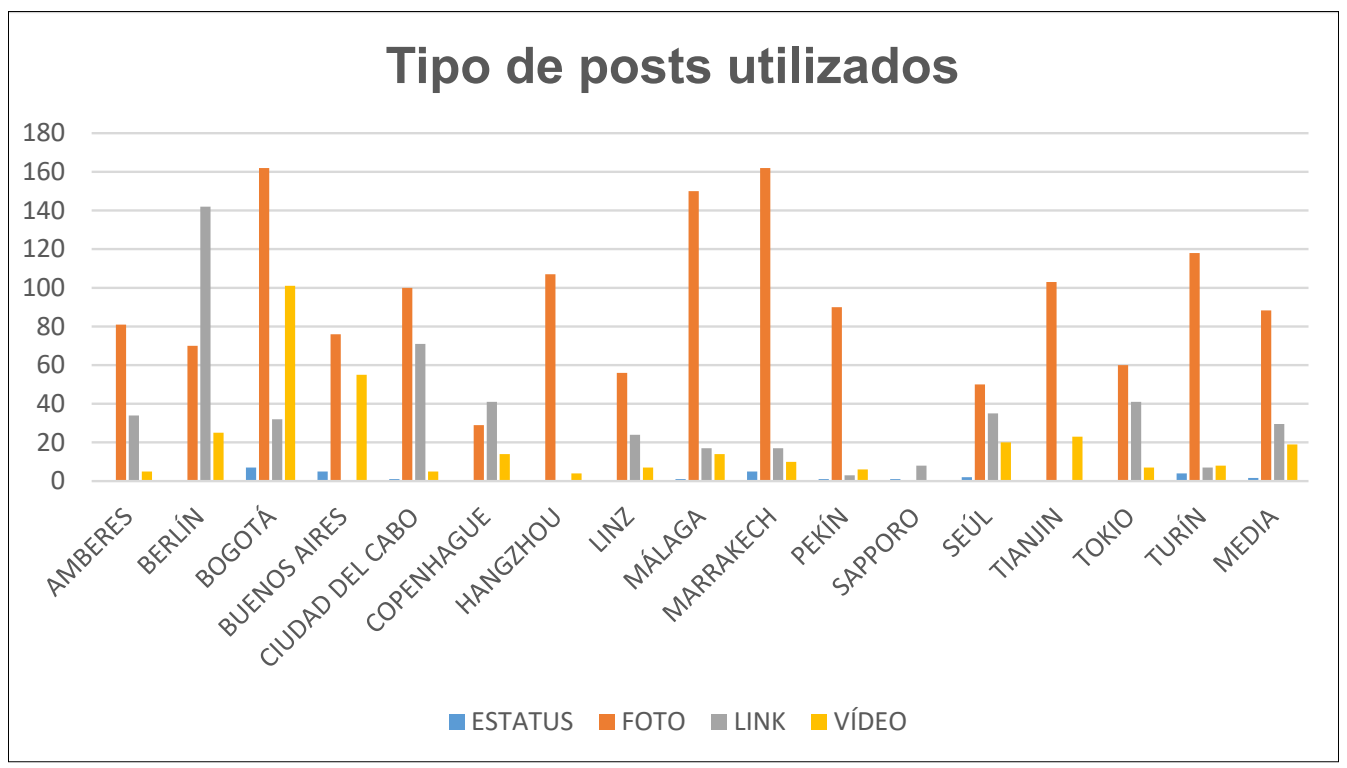

Fuente: elaboración propia

Por otra parte, el $81,2 \%$ de los destinos usan post con enlaces o links a otras informaciones. La media de este tipo de post por destino es de 29,5. Muy por encima de esta media se encuentran Berlín (142), Ciudad del Cabo (71), Copenhague (41), Tokio (41) y Amberes (34). En el lado contrario, por debajo de la media están Pekín (3), Turín (7), Sapporo (8), Málaga (17) y Marrakech (17). Buenos Aires, Hangzhou y Tianjin no usan estos post con enlace.

Finalmente, el 93,5\% de los destinos usan vídeos en sus post. La media de este tipo de publicaciones por cada destino es de 19. Los que más utilizan este recurso son Bogotá (101), Buenos Aires (55), Berlín (25), Tianjin (23) y Seúl (20). Por debajo de la media se encuentran Hangzhou (4), Amberes (5), Ciudad del Cabo (5), Pekín (6) y Linz (7). Sapporo es el único destino que no usa el vídeo en sus post. Analizados los tipos de post publicados, se analiza también los tipos que generan más interactividad de los usuarios a través de la medición de los 'likes', comentarios y posts compartidos, realizada por la herramienta Fanpage Karma.

Los posts con mayor número de reacciones son aquellos que tienen fotos. De hecho, los posts con imágenes reciben una media de 695,87 reacciones. Destacan destinos como Hangzhou (6.470), Seúl (1.363) y Pekín (919). Hay otros, sin embargo, que se quedan muy lejos en cuanto al número de reacciones: Bogotá (10), Marrakech (11) y Turín (15) están muy por debajo de la media. Tras los posts con fotos, son los enlaces los que reciben mayor número de reacciones (una media de 243,5). Muy por encima de la media están Pekín (1.989), Seúl (696), Málaga (318) y Copenhague (291). Muy por debajo se 
encuentran Marrakech (5,6), Bogotá (28) o Hangzhou (32), pero hay destinos que ni siquiera reciben reacciones a este tipo de posts: Tianjin, Hangzhou y Buenos Aires.

Por contenido (Gráfico 3), la mayoría de los posts publicados por los destinos turísticos se refieren a patrimonio tangible (una media de 26,3 posts en el periodo analizado), seguido por los de paisaje $(18,7)$, agenda, $(15)$, clima $(13,8)$ y naturaleza $(12,1)$. A mayor distancia se encuentran los posts sobre servicios $(10)$, ocio $(7,4)$, mensajes institucionales $(6,3)$, patrimonio intangible $(6,2)$, deporte $(4,5)$, negocios $(2,5)$, información no turística $(1,6)$ y tecnología $(0,8)$.

Gráfico 3

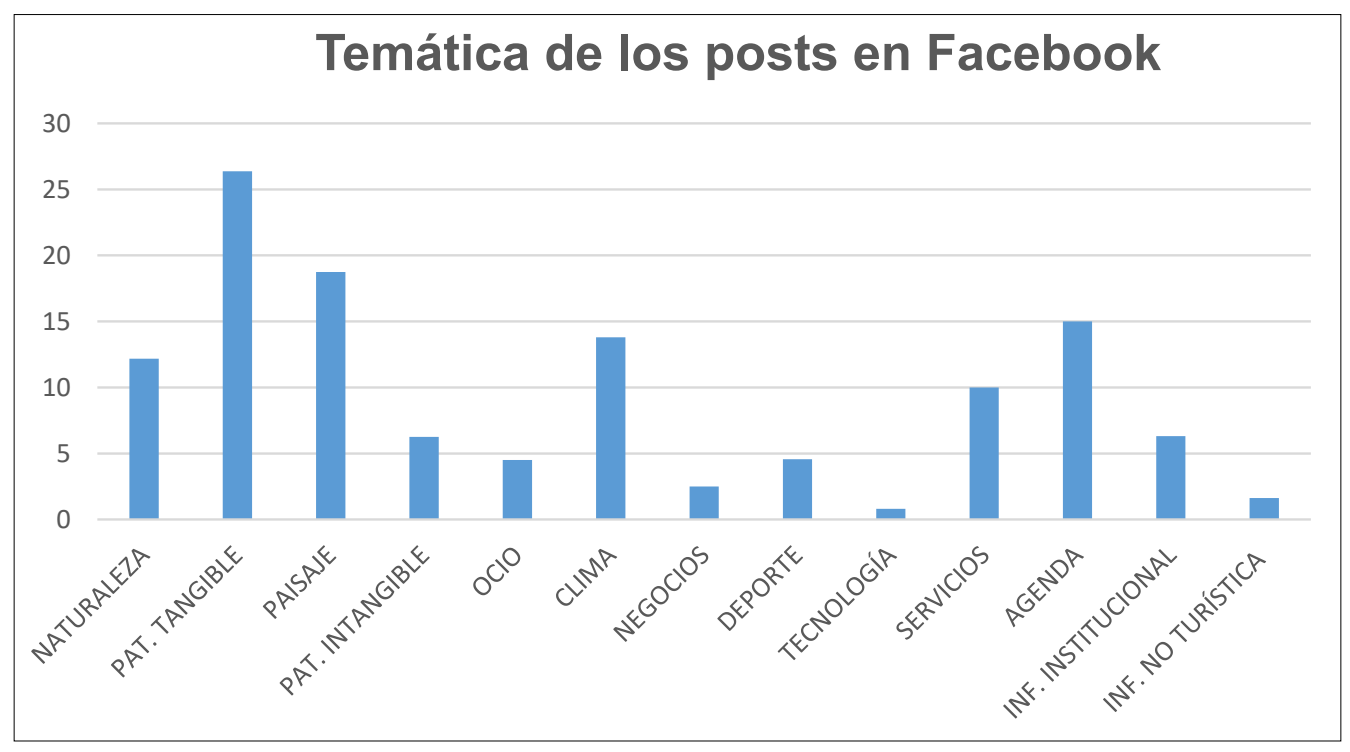

Fuente: elaboración propia

Las diferencias entre los destinos, sin embargo, son llamativas. Siendo los posts sobre patrimonio tangible los más numerosos en todos los destinos, las cifras varían desde los 45 de Tianjin hasta los 13 de Seúl. También existen notables diferencias entre los destinos a la hora de publicar posts sobre paisajes. Málaga (43) encabeza esta clasificación, seguido por Berlín (40) y Marrakech (32). En el extremo opuesto se encuentra Sapporo, que no utiliza ningún post sobre esta temática. La agenda como elemento de comunicación para los contenidos de los posts es usado por todos los destinos excepto Sapporo y Hangzhou. Turín (42), Málaga (26), Berlín (26) y Bogotá (23) son los destinos que publican más elementos de agenda en Facebook.

Cinco destinos no publican ningún post sobre clima: Seúl, Tianjin, Tokio, Turín y Buenos Aires. Sapporo solo publica uno y Pekín, dos. Por el contrario, Ciudad del Cabo publica post sobre el clima prácticamente todos los días (69), seguido por Berlín (22). Como se ha indicado anteriormente, también la naturaleza es un elemento ampliamente utilizado por los 
destinos turísticos urbanos en sus posts en Facebook. De hecho, todos los destinos analizados, excepto Sapporo, realizan algún tipo de publicación sobre sus atractivos naturales: Tokio ostenta el récord (32), seguido por Pekín (23).

Sobre los servicios, son Tokio (19), Berlín (17), Buenos Aires (15) y Turín (15) los destinos que más publican posts sobre esta temática. Pekín y Hangzhou, por el contrario, son los únicos destinos que no publican nada sobre servicios turísticos. En cuanto al ocio, son Tokio (14), Buenos Aires (10) y Berlín (9) los destinos que más publican posts con estos temas y Bogotá, Ciudad del Cabo y Sapporo no publican nada.

Los temas menos utilizados por los destinos turísticos para dar contenido a sus posts en Facebook son, como se ha indicado, los mensajes institucionales, el patrimonio intangible, el deporte, los negocios, la información no turística y la tecnología. Aun así, también existen notables diferencias entre los destinos. Copenhague, Berlín y Sapporo, por ejemplo, no usan este canal para informar sobre mensajes institucionales. Por el contrario, Bogotá lo usa hasta en 35 ocasiones, seguido por Marrakech (10) y Málaga (8).

Todos los destinos hablan también de su patrimonio intangible en sus posts: Buenos Aires lo hace hasta en 18 ocasiones, seguido por Copenhague (11) y Hangzhou (9). El deporte está muy presente en las informaciones de Bogotá (22 posts) y Málaga (13). Por el contrario, Amberes, Hangzhou y Sapporo no publican ningún post sobre asuntos deportivos. Tampoco Hangzhou, Málaga, Sapporo y Tokio publican ningún post sobre negocios. En el lado opuesto, Marrakech es el destino que más usa está temática (10), seguido por Amberes (8) y Bogotá (5).

Finalmente, la tecnología sólo es usada en los posts de Facebook por Bogotá, Hangzhou, Linz, Marrakech, Pekín, Sapporo, Seúl y Tianjin. La capital surcoreana bate el récord (5) seguido por Tianjin (2). Por otro lado, Amberes, Bogotá, Ciudad del Cabo, Hangzhou, Linz, Málaga, Marrakech, Pekín, Tokio y Turín son los destinos que publican información no turística en sus post en Facebook. Bogotá (6), Ciudad del Cabo (4) y Málaga (4) son los destinos que más usan este recurso.

Una vez analizada la interactividad según los tipos de posts, se analizó el contenido de los mismos buscando los temas que generación más reacciones entre los turistas. El patrimonio tangible (786,9 reacciones de media), la naturaleza (735) y el paisaje $(729,1)$ son los elementos más mencionados, si bien el ocio (513), el patrimonio intangible $(478,9)$ o la información institucional $(413,7)$ son también temas prominentes. Tras ellos se sitúan la tecnología $(325,3)$, el clima (172,6), el deporte $(102,6)$, la agenda $(83,6)$, los servicios $(75,7)$, los negocios $(57,8)$ y la información no turística $(48,1)$. El patrimonio tangible $(14,2)$ y el paisaje $(12,3)$ son, además, los temas que generan más comentarios y los que más se comparten: 54,6 veces de media el paisaje y 53 veces el patrimonio.

En cualquier caso, en términos absolutos los elementos que generaron más reacciones fueron una información sobre la Semana de Bienvenida a la Primavera de Seúl (40.083), una noticia sobre la visita de la bloguera Hallie Daily a Hangzhou (28.391), una exhibición en el jardín botánico de Pekín (9.009), la entrega de un prestigioso premio a un vino Chardonay de Ciudad del Cabo (3.319), una foto general de Berlín (2.643) y una foto compartida por un usuario de Málaga (2.548).

En general, se observa que los temas que generan más reacciones por parte de los usuarios son aquellos que se corresponden con los elementos más visuales (imágenes y vídeos) y que se corresponden a los atributos diferenciadores de los destinos (patrimonio tangible e intangible, naturaleza y paisaje). 


\section{Conclusiones y discusión}

Facebook sigue teniendo un papel muy relevante como herramienta de marketing para los destinos turísticos. De hecho, todos los destinos incluidos en el estudio 'City Tourism Performance Research' (UNWTO y WTCF, 2017) cuentan con su página oficial en esta red social, incluyendo los destinos chinos, pese a que en el gigante asiático la presencia de Facebook es testimonial.

Es más, dos ciudades chinas -Pekín y Hangzhou- se encuentran entre los tres destinos que más seguidores tienen en sus páginas de Facebook, lo que confirma que con independencia del peso que esta red social tenga en un país tiene un gran peso en el ámbito internacional como elemento de promoción turística. Lo resultados ponen de manifiesto, por otro lado, que el número de seguidores que un destino tenga en Facebook va más vinculado al tamaño del propio destino que a la actividad que se tenga en la red.

Los resultados muestran que la forma en la que Facebook se emplea por parte de los gestores de comunicación de los destinos urbanos varía de forma significativa. Las diferencias en el número de posts publicados por cada uno de los destinos son realmente importantes. De hecho, una mayor actividad en Facebook no conlleva un mayor número de seguidores ni, por supuesto, un mayor número de reacciones.

En este sentido, nuestra investigación coincide con la realizada por Mariani et al. (2016), que indicaba que la alta frecuencia de publicación suele tener un impacto negativo en el compromiso. Igualmente, la clasificación de un destino en llegadas de turistas no dicta una estrategia más desarrollada. Así, como apuntaban Hays et al. (2013), los destinos pequeños pueden ser más innovadores. En cualquier caso, esta forma de actuar demuestra nuestra hipótesis inicial de que la labor de los destinos en Facebook sigue siendo más intuitiva que estratégica.

Sí se evidencia un avance importante en el uso de imágenes para reforzar el mensaje que se quiere transmitir a través de Facebook. Más de seis de cada diez posts publicados llevan fotografías y todos los destinos, excepto Sapporo, que es la ciudad con una menor tasa de actividad en esta red, usan este recurso. Estos resultados contradicen lo expuesto por Martínez-Valerio (2012) en 'Estrategias de promoción turística a través de Facebook', que establecía que los destinos no prestaban una gran atención al uso de imágenes en Facebook.

El uso de fotografías es, además, fundamental. Ya White (2010), en una etapa muy inicial de la aparición de Facebook, había concluido que las imágenes tomadas, mostradas y grabadas en Facebook refuerzan la experiencia de viaje para el turista; y cómo, además, estas imágenes pueden influir en las decisiones de viaje de quienes ven las fotos.

Sin embargo, pese a la gran capacidad que tienen las imágenes para comunicar valores emocionales, como indicaban Míguez-González y Huertas (2015), los destinos las siguen usando fundamentalmente para presentar sus atractivos patrimoniales o turísticos. De hecho, se ha comprobado que en muchos de los destinos sigue habiendo una falta de estrategia en el uso de estas imágenes, sin mucho criterio, como ya establecía Huertas (2016).

Mariani, Mura y Di Felice (2018) habían establecido que los destinos usan Facebook con un enfoque de arriba a abajo y que el contenido espontáneo generado por los usuarios casi no tiene cabida. En este sentido, concluimos que Facebook sigue siendo más utilizado como canal de información que como herramienta de interacción o relaciones públicas con 
los potenciales turistas, en línea con Mariné-Roig y Huertas (2016). De hecho, la agenda, la información climática o los mensajes institucionales siguen teniendo gran peso en el contenido.

No obstante, parece haberse producido un avance en el uso de elementos que ayudan a comunicar la marca. Así, la mayoría de los posts publicados por los destinos turísticos se refieren a patrimonio tangible, que suele vincularse a los elementos representativos del destino y a los valores identificativos de la marca. Estos temas son, además, los que más reacciones generan por parte de los usuarios, por lo que los destinos deberían hacer un esfuerzo mayor para comunicar los valores que les diferencian de sus competidores.

Por otro lado, pese a que las imágenes o comentarios compartidas por los propios usuarios se cuelan en la clasificación absoluta de elementos que más reacciones producen, resulta evidente que el modelo uno-muchos continúa establecido en la promoción turística de las ciudades. Así, coincidimos con Martínez-Valerio (2012) en que los responsables de las páginas no utilizan las herramientas como elementos de interacción ni propician los debates.

En este sentido, concluimos que los destinos deberían ser más innovadores y creativos, propiciando la interacción con sus usuarios mediante herramientas de fácil acceso, como concursos, encuestas de opinión o juegos, que facilitarían la participación de sus potenciales turistas y les proporcionaría información sobre sus perfiles. Esta información, a su vez, permitiría definir mejor las necesidades de los turistas y atender su búsqueda de experiencias.

Igualmente, para reforzar los valores emocionales del destino, que son los que crean una relación más fuerte con los turistas, las OMD deberían compartir las experiencias que los viajeros publican en los medios sociales. Como se ha indicado, las experiencias y las imágenes cobran un especial protagonismo especialmente si estos proceden de los propios turistas. De esta forma, se inventiva la participación al tiempo que se genera una mayor visibilidad del destino entre los usuarios.

Además, para incrementar la interacción los destinos deberían hacer más preguntas a sus usuarios, responder los comentarios, compartir sus informaciones, agradecer las opiniones y estrechar cada vez más las relaciones con los turistas. Finalmente, los vecinos y residentes son los que mejor conocen los destinos turísticos y pueden convertirse en grandes prescriptores, por lo que deberían incluirse en la estrategia de comunicación de estos destinos en Facebook.

\section{Referencias bibliográficas}

Altamirano, V. \& Túñez-López, M. (2016). Promoción y difusión turística en los países de Iberoamérica a través de los medios sociales. International Journal of Information Systems and Tourism (IJIST), 1 (1), pp. 76-90.

Alvarado, P. (2012). Impacto de las redes sociales sobre las decisiones de los agentes. Bogotá: Unidad de Informática y Comunicaciones de la Facultad de Ciencias Económicas de la Universidad Nacional de Colombia, pp. 1-30.

Beerli, A. y Martín, J. D. (2004). Tourists characteristic and the perceived image of tourist destinations: a quantitative analysis -A case study of Lanzarote, Spain. Tourism Management, 25, pp. 623-636.

Bigné, J., Isabael Sánchez, M. Y Sánchez, J. (2001). Tourism image, evaluation variables and after purchase behaviour inter-relationships. Tourism Management, 22, pp. 607-616. 
Blain, C., Levy, S. E. y Brent Ritchie, J. R. (2005). Destination Branding: Insights and Practices from Destination Management Organizations. Journal of Travel Research, 43, pp. 328-338.

Buhalis, D. \& Law, R. (2008). Progress in information technology and tourism management: 20 years on and 10 years after the Internet - the state of eTourism research. Tourism Management, 29 (4), pp. 609-623.

Castells, M. (2001). La galaxia Internet. Reflexiones sobre Internet, empresa y sociedad. Barcelona: Plaza Janés.

Crompton, J. (1992). Structure of vacation destination choice sets. Annals of Tourism Research, 19, pp. 420-434.

Curty, R. y Zhang, P. (2011). Social commerce: Looking and forward. Proceedings of the American Society for Information Science and Technology, 48 (1), pp. 8-10.

De San Eugenio, J. (2011). Comunicación y Territorio. En De San Eugenio, J. (Ed.), Manual de comunicación turística: de la información a la persuasión, de la promoción a la emoción, pp. 53-72. Girona: Documenta.

Domínguez, T. \& Araújo, N. (2012). El fenómeno 2.0 en el sector turístico. El caso de Madrid 2.0. Pasos. 10 (3), pp. $225-237$. FACEBOOK. (2017). Stats. Recuperado de http://newsroom.fb.com/company-info

Fernández-Cavia, J. (2011). Ciudades, regiones y países como marcas: luces y sombras del place branding. En De San Eugenio-Vela (Ed.), Manual de comunicación turística: de la información a la persuasión, de la promoción a la emoción (pp. 103-113). Girona: Documenta

Fernández-Cavia, J. \& Huertas, A. (2009). City brands and their communication through websites: identification of problems and proposals for improvement. En Torres, T.; Gascó, M. (Eds.), Information communication technologies and city marketing: Digital opportunities for cities around the world (pp.1174-1297). New York: IGI Global.

Fernández-Cavia, J. \& Huertas, A. (2014). La gestión de las marcas de destino y de territorio desde la perspectiva de las relaciones públicas. Comunicació: Revista de Recerca i d'Análisi, 31 (1), pp. 9-26.

Folgado, J. A., Oliveira. P. A. y Hernández, J. M. (2012). Imagen del destino y marca turística: sinergias e implicaciones. Tourism \& Management Studies, pp. 904-914.

Giraldo, C. y Martínez, S. (2017). Análisis de la actividad y presencia en Facebook y otras redes sociales de los portales turísticos de las comunidades autónomas españolas. Cuadernos de turismo, 39, pp. 239-264.

Hays, S., Page, S. J., \& Buhalis, D. (2013). Social media as a destination marketing tool: its use by national tourism organisations. Current issues in tourism, 16 (3), pp. 211-239.

Huertas, A. (2014). La comunicación de los territorios, los destinos y sus marcas. Guía práctica de aplicación desde las relaciones públicas. Barcelona: DIRCOM-UOC.

Huertas, A. (2016). La comunicación de los destinos turísticos y sus marcas a través de los medios sociales. Tarragona: Universitat Rovira i Virgili.

Hvass, K. A. \& Munar, A. M. (2012). The takeoff of social media in tourism. Journal of vacation marketing, 18 (2), pp.93-103. Igartua, J. J. (2006). Métodos cuantitativos de investigación en comunicación. Barcelona: Bosch. 
INTERNET WORLD STATS. (2018). Internet Usage Statistics. Recuperado de http:/ /www.internetworldstats.

Krippendorff, K. (2001). Metodología de análisis de contenido. Teoría y práctica. Barcelona: Paidós.

Lange-Faria, W. \& Elliot, S. (2012). Understanding the role of social media in destination marketing. Tourismos: an international multidisciplinary journal of tourism, 7 (1), pp. 193-211.

Leung, D., Law, R., Van Hoof, H. \& Buhalis, D. (2013). Social media in tourism and hospitality: A literature review. Journal of Travel \& Tourism Marketing, 30 (1-2), pp. 3-22.

Lim, Y., Chung, Y. \& A Weaver, P. (2012). The impact of social media on destination branding: Consumer-generated videos versus destination marketer-generated videos. Journal of Vacation Marketing, 18 (3), pp. 197-206.

Mangold, W. G. \& Faulds, D. J. (2009). Social media: the new hybrid element of the promotion mix. Business Horizons, 52 (4), pp. 357-365.

Mariani, M. M., Di Felice, M. y Mura, M. (2016). Facebook as a destination marketing tool: Evidence from Italian regional Destination Management Organizations. Tourism Management, 54, pp. 321-343.

Mariani, M. M., Mura, M. y Di Felice, M. (2018). The determinants of Facebook social engagement for national tourism organizations' Facebook pages: A quantitative approach, Journal of Destination Marketing and Management, 8, pp. 312-325.

Mariné-Roig, E. \& Huertas, A. (2016). Metodologías de análisis. En A. Huertas (Ed.), La comunicación de los destinos turísticos y sus marcas a través de los medios sociales (pp. 9-16). Tarragona: Universitat Rovira i Virgil.

Martínez-Sala, A. M. \& Campillo-Alhama, C. (2018). La gestión de las redes sociales turísticas desde la perspectiva de las relaciones públicas 2.0: la importancia de diálogo. Revista Internacional de Relaciones Públicas, 8 (16), pp. 5-26.

Martínez-Valerio, L. (2012). Estrategias de promoción turística a través de Facebook. Palabra clave, 15 (2), pp. 318-338.

Mendes Thomas, G., Augusto Biz, A. \& Gândara, M. G. (2013). Innovación en la promoción turística en medios y redes sociales. Un estudio comparativo entre destinos turísticos. Estudios y perspectivas en turismo, 22 (1), pp. 102-119.

Miguéns, J., Baggio, R. \& Costa, C. (2008). Social media and tourism destinations: TripAdvisor case study. Advances in Tourism Research, 26 (28), pp. 1-6.

Míguez, M. I. y Huertas, A. (2015). The power of photograhs in the communication and public relations of tourist destinations and their brands through Facebook and Flickr. Catalan journal of communication \& cultural studies, 7 (2), pp. 197-215.

Miguez, M. I., Mariné, E. \& Huertas, A. (2014). ¿ Utilizan los destinos turísticos los medios sociales para crear diálogo con sus públicos? Estudio de los top post de Facebook y Twitter de los destinos turísticos españoles. En TURITEC 2014. X Congreso de Turismo y Tecnologías de la Información y las Comunicaciones, (pp. 108-121). Málaga: Universidad de Málaga. Mill, R. C. \& Morrison, A. M. (2012). The tourism system. Dubuque, Iowa: Kendall.

Morgan, N., Pritchard, A. \& Pride, R. (2011). Destination brands: Managing place reputation. Oxford: Butterworth-Heinemann. 
Munar, A. M. y Jacobsen, S. J. K. (2014). Motivations for sharing tourism experiences through social media. Tourism Management, 43 , pp. $46-54$

Observatorio de la redes sociales (2019) Recuperado de https://iabspain.es/observatorio-sectorial-de-redes-sociales-de-iab-spain-datos-enero-2019/

Orellana, D. M. y Sánchez, M. C. (2006). Técnicas de recolección de datos en entornos virtuales más usadas en la investigación cualitativa. Revista de Investigación Cualitativa, 24 (1), pp. 205-222.

Paniagua, F. J. \& Huertas, A. (2018). El contenido de los medios sociales de los destinos turísticos y la búsqueda de información de los usuarios. Cuadernos de Turismo, 41, pp. 513-534.

Piñeiro, M. (2012). ¿Cómo conseguir la mejor imagen de marca con las redes sociales? Concepto 05 Agencia de marketing online. Recuperado de http://www.concepto05. com/2012/04/como-conseguir-la-mejor-imagen-de-marca-con-las-redes-sociales/

Pike, S. y Page, S. (2014). Destination Marketing Organizations and destination marketing: A narrative analysis of the literature. Tourism Management, 41, 202-227.

Rieder, B. (2013). Studying Facebook via data extraction: the Netvizz application. En WebSci ' 13 Proceedings of the 5th Annual ACM Web Science Conference (pp. 346-355). Nueva York: Association for Computing Machinery (ACM).

Rodríguez, F. y De La Morena, M. (2014). Gestión de marca y redes sociales. Análisis y monitorización de la cuenta de Twitter @Renfe. En Díaz Cuesta, J. y Gaona Pisonero, C. (Ed.), Creatividad e innovación en el espacio publicitario (pp. 137-159). Madrid: ACCI.

Rodríguez, F., Llorente, C. y García, M. L. (2012). Fundamentos de la Eficacia Publicitaria y el Retorno de la Inversión. Madrid: Delta Publicaciones.

Sanmartín, J. (Ed). (2012). Discurso turístico e Internet. Madrid/Frankfurt: Iberoamericana Vervuert.

Santo, C. (2014). Redes sociales y móviles, las nuevas cartas de navegación de viajeros y turistas. Puromarketing.com. Recuperado de http://www.puromarketing. com/38/18284/sociales-moviles-nuevas-cartas-navegacion-viajeros-turistas. html

Stankov, U., Klauco, M., Vujicic, M., Vasiljevic, D. y Dragicevic, V. (2016). National parks are going social? An exploratory study of former Yugoslav countries on Facebook. En: Monitoring and Management of Visitors in Recreational and Protected Areas, pp. 79-81. Novi Sad: University of Novi Sad, Faculty of Sciences.

Sparkler (2014). Facebook Travel: Near And Now Insight Report. Recuperado de: https://issuu.com/sparkler-for-facebook/ docs/facebook_travel_near_and_now/23

UNWTO (1998). Turismo Panorama 2020. Madrid: UNWTO.

UNWTO y WTCF (2017). City Tourism Performance Research. Madrid: UNWTO.

UNWTO (2018). UNWTO Annual Report 2017. Madrid: UNWTO. 
White, L. (2010). Facebook, friends and photos: A snapshot into social networking for generating travel ideas. En Sharda, N. (Ed.). Tourism informatics: Visual travel recommender systems, social communities and user interface design. Hershey, PA: IGI Global.

Wichels, S. (2014). Cómo las redes sociales están cambiando la comunidad hotelera. Revista Internacional de Tecnología, Ciencia y Sociedad, 3 (2), pp. 11-24.

Wigley, S. \& Lewis, B. K. (2012). Rules of engagement: Practice what you tweet. Public Relations Review, 38 (1), pp. $165-167$.

Xiang, Z. \& Gretzel, U. (2010). Role of social media in online travel information search. Tourism Managament, 31 (2), pp. 179-188.

Xu, J. (2010). Social media influence on government affairs. Public Relations Magazine, 6 (13).

Zerfass, A., Moreno, A., Tech, R., Vercic, D. \& Verhoeven, P. (2017). European Communication Monitor 2017. Brussels: EACD / EUPRERA, Quadriga Media. 